\title{
Kinetic and Mechanistic Investigation on the Oxidative Reactions of Aromatic Secondary Alcohols by Polymer Supported Agent
}

\author{
VILAS Y. SONAWANE \\ Department of Chemistry, B. Raghunath Arts, Commerce and Science College, \\ Parbhani - 431 401, Maharashtra, India \\ sonawane_vy@rediffmail.com
}

Received 20 April 2014 / Accepted 2 May 2014

\begin{abstract}
The kinetic of chromium(VI) catalyzed oxidation of aromatic secondary alcohols has been studied by the rate of disappearance of $[\mathrm{Cr}(\mathrm{VI})]$. The reaction is zero order with respect to [Cr(VI)]. The reagent supported on anion exchange resin was found to be more efficient in the oxidation reaction. The reagent is very easily separated from the reaction mixture and can be manually removed from the reaction mixture, which remains clear during and after the reaction. The kinetics of oxidation of 4-bromophenylethanol, 4-chlorophenylethanol and 4-iodophenylethanol with chromic acid supported on anion exchange resin like Amberlite IRA $402\left[\mathrm{Cl}^{-}\right]$in 1, 4-dioxane has been studied. The reaction is found to be of zero order each in concentration of alcohol and oxidant. The reaction constants involved in the mechanism and the activation parameters have been calculated.
\end{abstract}

Keywords: Kinetic, Mechanistic investigation, Thermodynamic parameters, Secondary alcohols

\section{Introduction}

Chromium compounds have been used in aqueous and non-aqueous medium for the oxidation of a variety of organic compounds. Chromium compounds especially chromium(VI) reagents and capable of oxidizing almost all the oxidative organic functional groups. The development of newer chromium(VI) reagents for the oxidation of organic substrates continues to be of interest ${ }^{1-8}$.

In recent years, a number of chromium(VI) containing compounds like tri/tetralkylammonoium halachromates have been used as oxidant for the oxidation of various organic subtracts. Some of the new alkyl ammonium halo chromates like tertaethyl-ammoniumbromochromate, tributylammoniumchlorochromate, tripropylammonium fluoroc hromate and triethylammonium chlorochromate have been used to study the kinetics of oxidation of various organic compounds ${ }^{9-12}$.

In the present investigation, we now report the oxidation of secondary aromatic alcohols by polymer- supported chromic acid on Amberlite IRA $402\left[\mathrm{Cl}^{-}\right]$strong base anion exchange resin are supported on chromium(VI) oxide and it used as an oxidant. 


\section{Experimental}

All reagents used were of highest purity available. Aqueous solution of chromium trioxide (S.Merck, G.R.) was prepared always afresh and other required solutions are standardized iodimerically.

\section{Preparation of supported oxidizing agent}

The supported oxidizing agent was prepared by reported method ${ }^{13-15}$. The chloride form of Amberlite IRA $402\left[\mathrm{Cl}^{-}\right]$(a macro reticular anion exchange resin) containing a quaternary ammonium group was stirred with a saturated solution of chromium trioxide in water for $30 \mathrm{~min}$ at room temperature using a magnetic stirrer. The chloride ion was readily displaced and $\mathrm{HCrO}_{4}^{-}$form of resin was obtained in $40 \mathrm{~min}$. The resin was successively rinsed with water, acetone and THF and finally dried in vaccum at $323 \mathrm{~K}$ for $5 \mathrm{~h}$. The dried form of the resin was stored and used throughout the kinetic study.

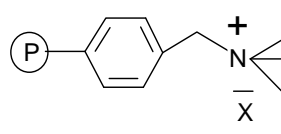

$[\mathrm{X}=\mathrm{Cl}]$

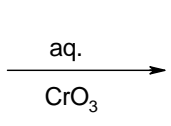

Polymer supported oxidizing agent

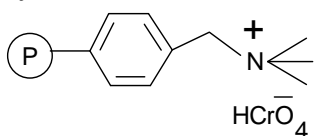

$\mathrm{HCrO}_{4}$

\section{Determination of the capacity of chromate form of the polymeric reagent}

The capacity of the chromate form of Amberlite IRA $402\left[\mathrm{Cl}^{-}\right]$polymeric reagent was determined by iodometrically. The capacity of the chromate form of resin was $1.75 \mathrm{eq} / \mathrm{L}$ and used for kinetic study throughout work. The loading was also determined by elemental nitrogen analysis and was found to be $2.45 \mathrm{eq} / \mathrm{L}$.

\section{Kinetic study}

The reaction mixture for the kinetic run was prepared by mixing alcohol, oxidant and solvent. The reaction was carried out either constant stirring using magnetic stirrer and at a constant temperature $318 \pm 1 \mathrm{~K}$. At different time interval, the reaction mixture was withdrawn using a micropipette. The aliquot thus withdrawn was taken in a stoppered test tube containing $5 \times 10^{-3} \mathrm{dm}^{3}$ of 1, 4-dioxane and subjected to spectral analysis. The absorbance of the product formed was measured using Schmadzu 1800 UV-Visible spectrophotometer.

\section{Induced polymerization test}

Test for free radicals was carried out by taking aromatic primary alcohol, 1:4dioxane and chromium(VI) in a thumberg tube and acrylonitrile in a bent tube. After evacuating the system the solutions were oxidized by tilting the tube. The reaction mixture was kept aside and even after 24 hours precipice was observed indicating the presence of free radicals ${ }^{16-17}$.

\section{Product analysis}

The oxidation of all aromatic secondary alcohols leads to the formation of corrosponding acetophenone. The product formed was analyzed by their 2, 4-dinitrophenylhydrazine derivatives. The precipitated 2,4-dinitrophenylhydrazone (DNP) was filtered off, the product is then vacuum dried, weighed and recrystallised from alcohol. The yield of DNP recrystallisation with the DNP of corresponding acetophenone was 96-98\%. The product also identified either by comparison with authentic samples or by UV and elemental analysis. The IR spectra were recorded on a Jasco FT-IR spectrophotometer using $\mathrm{KBr}$ pellets. The melting point of 2, 4-dinitrophenylhydrazone derivative of various aromatic secondary alcohols shown in the following Table 1. 
Table 1. Melting point of 2, 4-dinitrophenylhydrazone derivatives of secondary alcohols

\begin{tabular}{lccc}
\hline $\begin{array}{l}\text { Melting point of 2,4 DNP hydrazone } \\
\text { Derivative }\end{array}$ & $\mathrm{K}$ & Yield in \% & U V spectrum $\lambda_{\max }$ \\
\hline 4-Bromoacetophenone & 237 & 96 & 242 \\
4-Chloroacetophenone & 245 & 94 & 259 \\
4-Iodoacetophenone & 274 & 98 & 278 \\
\hline
\end{tabular}

\section{Results and Discussion}

\section{Effect of varying weights of oxidant}

The order with respect to weights oxidant is zero, as the plots of absorbance against time were linear in all runs and observed rate constant are fairly constant between 50 to $80 \times 10^{-6} \mathrm{~kg}$ of oxidant at constant concentration of solvent $\left(1,4-\right.$ dioxane, $\left.5 \times 10^{-3} \mathrm{dm}^{3}\right)$ and aromatic secondary alcohols $\left(12.3 \times 10^{-3} \mathrm{~mol} / \mathrm{dm}^{-3}\right)$, the effect of varying weights of oxidant on zero order rate constant as shown in Table 2.

Table 2. Effect of varying weights of oxidant on reaction rate at $318 \mathrm{~K}$

\begin{tabular}{|c|c|c|c|c|}
\hline Rate constant & \multicolumn{4}{|c|}{$\mathrm{k} \times 10^{-4} \mathrm{~mol} \mathrm{dm}^{-3} \mathrm{~s}^{-1}$} \\
\hline Oxidant $\times 10^{-6} \mathrm{~kg}$ & 50 & 60 & 70 & 80 \\
\hline 4-Bromophenylethanol & 1.85 & 1.92 & 1.95 & 1.99 \\
\hline 4-Chlorophenylethanol & 1.92 & 2.02 & 2.07 & 2.10 \\
\hline 4-Iodophenylethanol & 1.95 & 2.05 & 2.11 & 2.15 \\
\hline
\end{tabular}

Effect of varying concentrations of various aromatic secondary alcohols

At a varying concentration of 1-phenylethanol $\left(8.20\right.$ to $\left.20.4 \times 10^{-3} \mathrm{~mol} / \mathrm{dm}^{3}\right)$, constant weights of oxidant $\left(70 \times 10^{-6} \mathrm{~kg}\right)$ and constant concentration of solvent (1,4-dioxane, $\left.5 \times 10^{-3} \mathrm{dm}^{3}\right)$, zero order rate was observed (Table 3 ).

Table 3. Effect of varying concentrations of various aromatic secondary alcohols

\begin{tabular}{lcccc}
\hline \multicolumn{1}{c}{ Rate constant $\rightarrow$} & \multicolumn{4}{c}{$\mathrm{k} \mathrm{x} \mathrm{10^{-4 }} \mathrm{mol} \mathrm{dm}^{-3} \mathrm{~s}^{-1}$} \\
\hline Conc. of alcohol $\rightarrow$ & $\begin{array}{c}8.20 \times 10^{-3} \\
\mathrm{~mol} / \mathrm{dm}^{3}\end{array}$ & $\begin{array}{c}12.3 \times 10^{-3} \\
\mathrm{~mol} / \mathrm{dm}^{3}\end{array}$ & $\begin{array}{c}16.4 \times 10^{-3} \\
\mathrm{~mol} / \mathrm{dm}^{3}\end{array}$ & $\begin{array}{c}20.4 \times 10^{-3} \\
\mathrm{~mol} / \mathrm{dm}^{3}\end{array}$ \\
\hline 4-Bromophenylethanol & 1.65 & 1.69 & 1.73 & 1.79 \\
4-Chlorophenylethanol & 1.78 & 1.89 & 1.95 & 2.05 \\
4-Iodophenylethanol & 1.94 & 1.99 & 2.01 & 2.08 \\
\hline
\end{tabular}

Effect of varying dielectric permittivity of the medium on the reaction rate

It was found that the dielectric constant of the medium is increased, this including $r^{*}<r$ (Where $\mathrm{r}^{*}$ and $\mathrm{r}$ refer to the radii of the reactant species and activated complex respectively) at constant concentration of various aromatic secondary alcohol $\left(12.3 \times 10^{-3} \mathrm{~mol} / \mathrm{dm}^{3}\right)$ and constant concentration of oxidant $\left(70 \times 10^{-6} \mathrm{Kg}\right)$, solvent $\left(5 \times 10^{-3} \mathrm{dm}^{3}\right)$ as shown in Table 4.

Table 4. Effect of varying dielectric permittivity

\begin{tabular}{lcccc}
\hline Rate constant $\rightarrow$ & \multicolumn{4}{c}{$\mathrm{k} \mathrm{x} \mathrm{10} 0^{-4} \mathrm{~mol} \mathrm{dm}^{-3} \mathrm{~s}^{-1}$} \\
\hline Solvent $\left[5 \times 10^{-3} \mathrm{dm}^{3}\right] \rightarrow$ & $\mathrm{C}_{6} \mathrm{H}_{12}$ & $\mathrm{CCl}_{4}$ & $1,4-$ Dioxane & $\mathrm{CHCl}_{3}$ \\
\hline Dielectric constant $\rightarrow$ & 2.00 & 2.17 & 2.28 & 4.81 \\
\hline 4-Bromophenylethanol & 1.25 & 1.59 & 2.46 & 2.86 \\
4-Chlorophenylethanol & 1.29 & 1.35 & 1.56 & 1.78 \\
4-Iodophenylethanol & 1.35 & 1.55 & 1.89 & 2.10 \\
\hline
\end{tabular}




\section{Effect of varying temperature}

The reaction was carried out at four different temperatures under otherwise similar reaction conditions to study the effect of temperatures on the rate of reaction. It was observed that, the rate of reaction increased with an increase in the temperature (Table 5). The activation parameters such as energy of activation $(\mathrm{Ea})$, enthalpy of activation $\left(\Delta \mathrm{H}^{\#}\right)$, entropy of activation $\left(\Delta S^{\#}\right)$ and free energy of activation $\left(\Delta G^{\#}\right)$ the high positive values of free energy of activation indicates that the transition state is highly solved and frequency factor (A) were calculated by determining values of $\mathrm{k}$ at different temperatures (Table 6).

Table 5. Effect of varying temperature

\begin{tabular}{lcccc}
\hline \multicolumn{1}{c}{ Substrate } & \multicolumn{4}{c}{$\mathrm{kx}^{-4} 0^{-4} \mathrm{~mol} \mathrm{dm}^{-3} \mathrm{~s}^{-1}$} \\
& $313 \mathrm{~K}$ & $318 \mathrm{~K}$ & $323 \mathrm{~K}$ & $328 \mathrm{~K}$ \\
\hline 4-Bromophenylethanol & 1.95 & 2.12 & 2.43 & 2.78 \\
4-Chlorophenylethanol & 2.10 & 2.25 & 2.36 & 2.45 \\
4-Iodophenylethanol & 2.25 & 2.35 & 2.48 & 2.59 \\
\hline
\end{tabular}

Table 6. Thermodynamic parameters

\begin{tabular}{|c|c|c|c|c|c|}
\hline Substrate & $\begin{array}{c}\mathrm{Ea} \\
\mathrm{kJ} \mathrm{mol}^{-1}\end{array}$ & $\begin{array}{c}\Delta \mathrm{H}^{\#} \\
\mathrm{~kJ} \mathrm{~mol}^{-1}\end{array}$ & $\begin{array}{c}\Delta \mathrm{S}^{\#} \\
\mathrm{JK} \mathrm{mol}^{-1}\end{array}$ & $\begin{array}{c}\Delta \mathrm{G}^{\#} \\
\mathrm{~kJ} \mathrm{~mol}^{-1}\end{array}$ & $\begin{array}{c}\mathrm{A} \times 10^{-5} \\
\mathrm{~s}^{-1}\end{array}$ \\
\hline 4-Bromophenylethanol & 89 & 69 & -79 & 305 & 4.5 \\
\hline 4-Chlorophenylethanol & 94 & 73 & -86 & 315 & 5.5 \\
\hline 4-Iodophenylethanol & 98 & 79 & -95 & 325 & 5.9 \\
\hline
\end{tabular}

On the basis of above experimental results the following reaction (Scheme 1-5) is proposed for $\mathrm{Cr}(\mathrm{VI})$ catalyzed oxidation of various aromatic secondary alcohols. The mechanism is suggested in Scheme 5 and involves ester formation ${ }^{18,19}$.

1) The polymer supported reagent reacts with a molecule of alcohol to form a chromate ester.

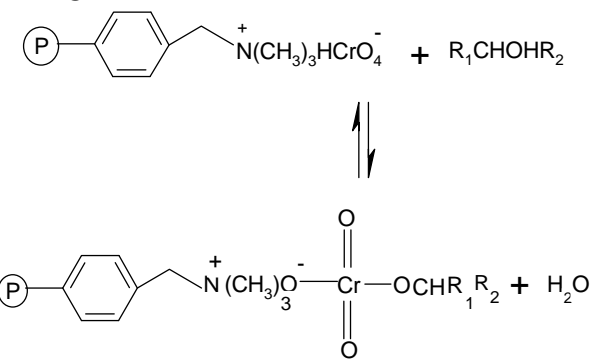

\section{Scheme 1}

2) The ester formed will decompose into ketone and the intermediate chromium(IV) will be formed in the second and slow step.

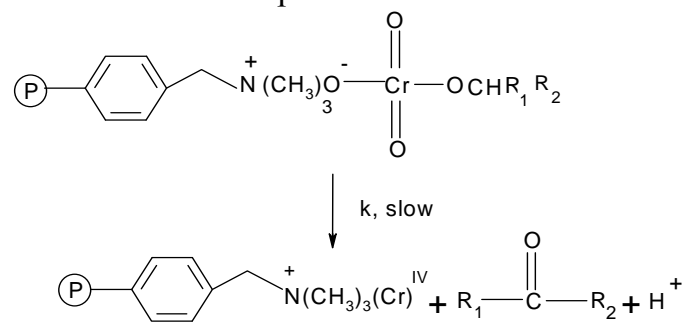

Scheme 2 
3) The intermediate chromium(IV) thus reacts with another alcohol molecule to produce a free radical species. The free radical species formation in the reaction was confirmed by the polymerization of added acrylonitrile or addition of acidified methanol into the reaction mixture.

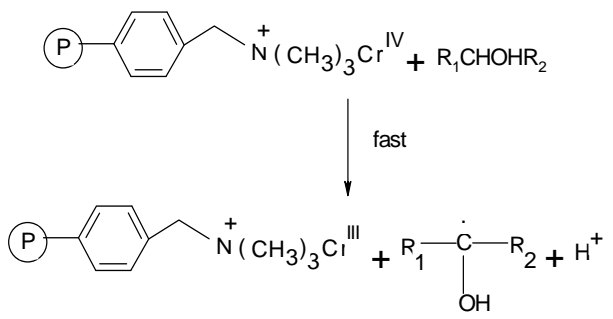

\section{Scheme 3}

4) Subsequently the free radical will react with another oxidant site in the polymeric reagent in a fast step leading to the formation of chromium(V).

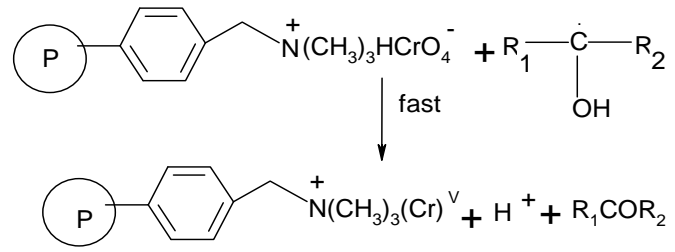

\section{Scheme 4}

5) The intermediate chromium(V) in the last step reacts with 1-phenylethanol produce acetophenone. The test for formation of chromium(V) and (IV) by the characteristic induced oxidation of iodide ${ }^{20}$ and manganese(II) ${ }^{21}$ were not probably due to heterogeneity of the reaction mixture.

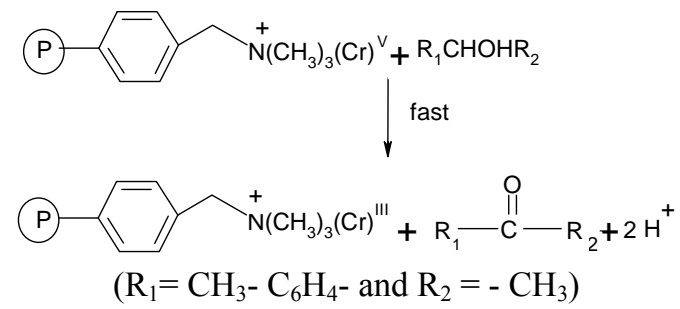

\section{Scheme 5}

\section{Conclusion}

The linearity of absorbance against time plots and constancy of the zero order rate constants indicate that the reaction neither depends on the polymeric reagents nor on the alcohol concentration. This anomalous nature of the reaction may be because of the fact that the oxidant is taken in the form of solid supported on polymer. Polymer supported oxidizing agent proved to be exclusively selective towards the oxidation of aromatic secondary alcohols, giving corresponding acetophenone as the only product ${ }^{22}$.

According to Scheme 5, a second order rate law is expected. But since the first step of ester formation occurs in solid phase and assuming that this equilibrium does not contribute to the rate of reaction. We obtained zero order dependence with rate constant $k$ of the second slow step in which product acetophenone was obtained. Based on the experimental observations a probable mechanism is suggested. 


\section{Acknowledgement}

The author is thankful to the University Grants Commission, New Delhi, India for the financial support of this major research project sanctioned F.No.42-253/2013(SR). The author is grateful to the C-MET, Pune, Maharshtra, India for providing some instrumental facilities.

\section{References}

1. Song W Y, Li W K and Jia C P, Chem J Chin Univ., 1999, 20(11), 1767-1771.

2. $\quad$ Song W Y and Liu H M, Chin J Inorg Chem., 2000, 16(4), 607.

3. Shan J H, Qian Q and Zhai T Y, Chin J Inorg Chem., 2003, 19, 843.

4. Lakshmi $\mathrm{S}$ and Renganathan $\mathrm{R}$, Int J Chem Kinet., 1996, 28(10), 713-720; DOI:10.1002/(SICI)1097-4601(1996)28:10<713::AID-KIN1>3.0.CO;2-Q

5. Corey E J and Schmidt G, Tetrahedron Lett., 1979, 20(5), 399-402; DOI:10.1016/S0040-4039(01)93515-4

6. Bhattacharjee M N and Choudhari M K, Dasgupta S D, Roy N and Khating D T, Synthesis, 1982, 1(7), 588-590; DOI:10.1055/s-1982-29872

7. Blaschke $G$ and Scriba G, Tetrahedron Lett., 1985, 24(52), 5855-5856; DOI:10.1016/S0040-4039(00)94219-9

8. Climinale F, Camporeale M, Mello R, Troisi L and Curci R, J Chem Soc., Perkon Trans., 1989, 2, 417.

9. Sharma G G and Mahanti M K, Bull Soc Chem Fr., 1991, 128, 449.

10. Balasubramanian K and Pratibha V, Indian J Chem., Sec B, 1986, 25, 326.

11. Narayana B and Tam Cherian, J Braz Chem Soc., 2005, 16197.

12. Buglas A J and Waterhouse J S, J Chem Edu., 1987, 64, 3712.

13. Cainelli G, Cardillio G, Orena M and Sardri S, J Am Chem Soc., 1976, 98, 6767.

14. Brunlet T, Jouitteau C and Gelhard G, J Org Chem., 1986, 51(22), 4016-4022; DOI:10.1021/jo00371a019

15. Mosher W A Clement H and Hillard R L, J Am Chem Soc., 1993, 29, 565.

16. Watanabe W and Westheimer F H, J Chem Phys., 1979, 61, 17.

17. Salunke M M, Salunke D G, Kanade A S, Mane R B and Wadgaonkar P P, Synth Commun., 1990, 20(8), 1143-1147; DOI:10.1080/00397919008052821

18. Matsuo J, Kawana A, Pudhon K and Mukaiyama T, Chem Lett., 2002, 250.

19. Hutchins R O, Natale N R, Jack Ohr and Cook W J, Tetrahedron Lett., 1977, 18(48), 4167-4169; DOI:10.1016/S0040-4039(01)83456-0

20. Hilage N P, Kakde S A, Sonawane V Y, J Indian Chem Soc., 2009, 86, 577-581.

21. Espenson J H, J Am Chem Soc., 1964, 85(86), 5101-5107; DOI:10.1021/ja01077a012

22. Sonawane V Y, Am J Chem., 2013, 3, 589-591. 